\title{
Study on Construction of Online Teaching Evaluation Index System of Independent Colleges
}

\author{
Huan Ji \\ Nanhang Jincheng College \\ Nanjing, China 211156
}

\begin{abstract}
The online teaching evaluation index system of independent colleges is taken as the object of analysis in this paper. A new set of online teaching evaluation index system is constructed by using Delphi method and analytic hierarchy process, including four first-grade indexes and fourteen secondgrade indexes, reflecting teaching quality, teaching content, teaching method and teaching effect respectively. In addition, value is assigned to index weight scientifically and rationally. It is expected that the new online teaching evaluation index system constructed in this paper has a good orientation and outstanding operational effect, and can be applied to the actual teaching evaluation management.
\end{abstract}

Keywords-independent colleges; online teaching evaluation; index system

\section{INTRODUCTION}

The most widely used implementation model of students' teaching evaluation index system in colleges in our country is Taylor's goal-oriented model, namely "index system - weight coefficient - quantification method - weighted sum". This model is centered on the goal of education, and the evaluation process is to analyze and study the realization degree of results of educational activities relative to educational goals.

Independent colleges take the application-oriented talents cultivation and serving regional economic construction and development as the goal. According to relevant researches, "the characteristics of application-oriented talents cultivation focus on two aspects: one is the combination of academic, technical and vocational aspects, and the second is the enhancement of students' social adaptability and service ability. The most important characteristics differing applicationoriented talents and theory-oriented talents is practical teaching, and the main cultivation approach is the practical operative ability. The teaching content of shall be expanded from the original pure theoretical teaching to actual knowledge teaching. In addition to basic theoretical knowledge teaching, the actual knowledge is needed to be added constantly, to closely connect to practical applications. Therefore, it is indispensable to combine the factors of practice teaching in teachers' evaluation index system of independent colleges. Moreover, its importance in teaching evaluation index system of independent colleges shall be highlighted with emphasis.

\section{ClassifiCATION SYSTEM OF ONLINE EVALUATION INDEX SYSTEM OF INDEPENDENT COLLEGE}

The level of teaching ability of independent college teachers is mainly reflected in their design ability, expression ability, management ability and practical ability in teaching. Each aspect also includes segmentation indexes. (1). Design ability: design of teaching objectives, design of teaching content, design of teaching structure, and design of teaching methods and means; (2). expression ability: language expression ability, physical expression, etc.; (3). management ability: creating of teaching environment, maintenance of teaching order, communication between teachers and students etc.; (4). practical ability: operational ability, professional quality, vocational skills. To strengthen and enhance the ability of teachers, the abilities of above three aspects shall be elevated with emphasis. Therefore, when setting online teaching evaluation index system, the above three aspects shall be taken into full consideration, thus to achieve the enhancement of teachers' teaching ability through the research and construction of online teaching evaluation index system.

The construction of online teaching evaluation index system is to optimize the original online teaching evaluation index system, and to select the new online teaching evaluation indexes. The determination of index system is of great subjective arbitrariness, usually including empirical method and mathematical method. Although the mathematical method to determine index system can reduce the subjective arbitrariness of index system selection, the uniqueness of index system cannot be guaranteed as the sample collections adopted are different. However, empirical methods are used in practical research. This paper mainly uses the combination of empirical method and mathematical method to construct the online teaching evaluation index system of independent colleges.

\section{InDEX SySTEM OF ONLINE TEACHING EVALUATION INDEXES OF INDEPENDENT COLLEGES}

In order to promote talent cultivation target of independent colleges, to provide regional economic construction with excellent application-oriented senior specialized talents, and to meet the needs of local economic development, supervision of teaching quality shall be strengthened from cultivation of college students' operational ability, teaching of the course training link, as well as the cultivation of professional quality and professional skills. As a result, the online teaching 
evaluation index system of independent colleges that cultivate senior application-oriented talents shall increase the indexes of teaching links such as training and operational ability cultivation.

In order to realize the goal of cultivating high quality application-oriented talents in independent college, practice teaching is especially important. College practice teaching is diversified, including in-class and extra-curricular experiments, training, practice, research, painting practice, curriculum design, and some are independent classes, some are integrated with theory class. College practice teaching plays a direct role in fostering, training, forming and improving the application ability and employment ability of college students. The quality of practical teaching directly affects the overall teaching quality of independent colleges. In order to integrate practical teaching into the whole process of teaching and talent cultivation to really achieve the organic integration of common knowledge and specialized knowledge, adding relevant requirements of practice teaching into teaching evaluation index system is not only very important but also extremely urgent.

According to the principle of online teaching evaluation index system setting, in the process of designing the index system, students have been surveyed in the early stage to fully understand the subject receiving education - the students' views on teachers' teaching, and the teaching process and teaching effect the students expect. Then the online teaching evaluation index system of independent colleges is established after surveying a large number of data, text data and some views and opinions of experts in combination with the index system analysis theory.

According to the investigation and survey of students' online teaching evaluation conducted in the process of daily teaching management, the study and analysis of specific content of various links of teaching activities, combined with the current educational development direction and the talent cultivation goal of higher education, the online teaching evaluation index system of independent colleges shall be constructed starting from four aspects, namely teaching attitude, teaching content, teaching method and teaching effect, and each aspect includes subdividing indexes.

Indexes relating to talent cultivation characteristics of the colleges are added, and the indexes relating to basic elements of teaching quality are sorted out based on the previous online teaching evaluation indexes of independent colleges, through consulting large number of literatures in terms of teachers' basic teaching skills and qualities, by reference to some indexes relating to basic factors of teaching quality. Finally, the following indexes are primarily selected after further analysis, removing some obvious overlapping, combined with college students' knowledge structure characteristics and cognitive level, and improving some indexes that are easy to be subject to divergences and difficult to be judged: First, the academic attitude (such as teaching seriously with responsibility, or being involved in teaching), teaching level (such as expressing clearly with accurate language, teaching humorously, teaching with emotions and teaching in accordance with students' aptitude), being a model for others (such as rigorous scholarship, teaching by personal example as well as verbal instruction, discipline and punctuality, paying attention to manners and appearance), job placement and correction (such as whether the amount is suitable or not), teacher-student relationship (respecting and believing in students, encouraging and guiding students), making sufficient preparation for class with normative teaching plans and teaching contents. Second, the teaching objectives formulated are in line with the syllabus and students' actual level, pay attention to the explanation of cutting edge knowledge of the subject, whether the teaching materials and reference material selected are appropriate, teaching schedule (such as appropriate progress, reasonable content allocation, having room for taking notes and thinking) and teaching method. Third, mastering of teaching methods (such as heuristic teaching, the use of cases, the organization of class discussions and other teaching methods), the use of teaching aids (such as exquisitely and skillfully made PPT with good sensory effect), classroom management (such as being good at mobilizing classroom atmosphere, dealing with students' misconduct timely and effectively), innovation and practice awareness cultivation (such as conducting teaching analysis in combination with examples, encouraging students to innovate and think, organizing classroom discussions, guiding students to practice after school, applying what they have learned for practical use) and teaching effect. Fourth, learning plays a promoting role in students' personality and becoming a useful person, the basic contents and relevant practice base can be mastered through learning, students' interest in this course can be enhanced through learning, the application methods of this course can be mastered through learning (such as application areas, application value, application means).

The characteristics of independent colleges as well as the talent cultivation objectives of independent colleges are taken into full consideration in this project based on literature research. And the online teaching evaluation index system of independent colleges is constructed using Delphi method, analytic hierarchy process and other methods on the basis of following the principles of teaching evaluation indexes' directionality, systematicness, and operability, combination of quantitative and qualitative, hierarchical and so on. The evaluation index system includes teaching accomplishment (weight 0.123), teaching content (weight 0.359), teaching methods (weight 0.193) and teaching effect (weight 0.325) as well as four first-grade indexes and 14 second-grade indexes. The consistency of all indexes of the index system $<0.1$ indicates the index weight is designed very well with good consistency.

The four first-grade indexes of online teaching evaluation are further subdivided. The online teaching evaluation indexes of independent colleges shall include teaching attitude (comprehensive weight 0.038), teaching level (comprehensive weight 0.061), being a model for others ((comprehensive weight 0.024$)$, whether the teaching materials and reference materials selected are appropriate (comprehensive weight 0.027), teaching schedule (comprehensive weight 0.048), important and difficult points of teaching contents (comprehensive weight 0.0126), practice teaching (comprehensive weight 0.068 ), the combination of in-class 
teaching and extracurricular teaching (comprehensive weight 0.090), mastering of teaching methods (comprehensive weight 0.102 ), the use of teaching aids (comprehensive weight 0.027 ), innovation and practice awareness cultivation (comprehensive weight 0.064 ), whether the basic content and relevant practice basis of this course can be mastered through learning (comprehensive weight 0.108), whether the interest in this course can be improved through learning (comprehensive weight 0.045 ), whether the application methods of this course can be mastered through learning (comprehensive weight 0.172 ), and 14 second-grade indexes.

\section{CONCLUSION}

The online teaching evaluation index system constructed in this study highlights the importance of practical teaching in the process of talent cultivation in independent colleges and increases relevant indexes of practical teaching, which is more in line with the talent cultivation objectives of independent colleges and the positioning of service area. The purpose is to make the online teaching evaluation system of independent colleges more scientific and rational, to improve the overall quality of teachers through online teaching evaluation by students, to build a scientific and systematic system which is more in line with the teacher management system of independent college, so as to promote the continuous progress of independent college education under public education system as well as the quality and quantity of talent cultivation, thus to promote teachers to improve teaching quality. But due to the limitation of time and its own level as well as many other factors, relevant theory of this study appears to be immature, some indexes seem to be somewhat abstract subjective, the results are not satisfactory enough, and the pilot evaluation practice is to be conducted on a wider range. But this is where needs to be studied in-depth in the future.

Students are the direct subjects participating in the online teaching evaluation, and they have the most profound feeling whether the teaching evaluation system is rational or not. In the evaluation process, students tend to make a subjective evaluation on whether the index system content and the weight are reasonable or not, such as index contents' coverage and rationality for the teaching activities, and whether the subjective evaluation distribution of indexes can reflect the emphasis of teaching activities and so on. Therefore, it needs to be verified in practice whether the constructed index system can play a good application effect, and be compared with the previous teaching evaluation index system in order to gain further insight into the strengths and weaknesses of the improved index system, and to gradually improve it. In the teaching process, the purpose of teaching is to better serve learning, so the quality of teaching directly affects the quality of learning, and the quality of learning is necessarily an important index measuring quality of teaching.

\section{REFERENCES}

[1] Zhang Rui. A Comparative Study of Chinese and Foreign Colleges' Evaluation [M]. Hangzhou: Zhejiang University Press, 2008.

[2] Feng Hui. Education Evaluation Computing [M]. Beijing: Higher Education Press, 2012.
[3] Establishment and Management Methods of Independent Colleges. Website of the Central People 's Government of the People' s Republic of China. http://www.gov.cn/flfg/200803/07/content_912242.htm.2008-2-22.

[4] Xu Weimin, Lin Weilian, Lou Xijin. Study on the Development and Operation of Independent Colleges [M]. Hangzhou: Zhejiang University Press, 2008.

[5] Jiang Rongping. Research on the Development of Teaching Evaluation Technology in Colleges [D]. Guangxi: Guangxi University for Nationalities, 2008.

[6] Gu Mingyuan. Chinese Education Dictionary [M]. Shanghai: Shanghai Educational Publishing House. 1998.

[7] Tao Xiping. Dictionary of Educational Evaluation [M]. Beijing: Beijing Normal University Press, 1998.

[8] John A. Centra. (1993). Reflective Faculty Evaluation: Enhancing Teaching and Deterring Faculty Effectiveness.San Francisco: JosseyBass.

[9] Sun Hechuan. International Comparative Study on Teacher Evaluation Index System [M]. Beijing: Commercial Press, 2011.

[10] Scriver,M.A Unified Theory Approach to Teacher Evaluation.Studies in Educational Evaluation, 1995, p: 29.

[11] Marsh, H. W. \& Dunkin, M. J. (1992). Students'evaluation of university teaching: a multidimensional perspective $[\mathrm{J}]$. Higher Education: handbook of research and practice, V01. 8, New York, Agarhon Press.

[12] Kolitch, Elaine, Dean, a. v. (1999). Student Ratings of Instruction in the USA: hidden assumption and missing conceptions about good's teaching[J]. Studies in Higher Education, V01. 24 Issue1; P27, 16.

[13] Masaki Kuwaku. Perspectives for Evaluating College Teachers [A] Masaki Onami. Selected Works of College Evaluation [c] eldell Institute. 2003.191.

[14] Ding Bo, LI Yiming. A Probe into the Evaluation System of Japanese College Students [J]. Journal of Luoyang Normal University, 2007, No.4: 144-146.

[15] Du Xingjun. Construction and Application of the Evaluation Index System of Teachers' Classroom Teaching Quality in an Independent College of a Medical University [D]. Xinjiang: Xinjiang Medical University, 2008.

[16] He Chunyan. Analysis of the Factors Affecting Online Teaching Evaluation Effect of Independent Colleges and the Improvement Measures [J]. Modern Enterprise Education. 2010,(16):159-160.

[17] Jiang Fanghua. Research on the Use Efficiency Evaluation System of College Educational Funds [D].Nanjing: Nanjing University of Science and Technology, 2011.

[18] Dai Yiming, Qiao Wangzhong. Study on the Evaluation Index System of Classroom Teaching Based on Delphi Method and Superiority Chart [J]. Education of Chinese Medicine, 2011, 30 (5): 8-11.

[19] Luo Yi. Research on the Optimization of College Students' Online Teaching Evaluation System - Taking Jiangxi Normal University as an Example [D]. Jiangxi: Jiangxi Normal University, 2013.

[20] Cheng shiping, Zhou Pingsheng, Cheng Li. On the Effect of Teaching Quality Improvement by Evaluating Teaching based on Learning [J]. Educational Circles, 2014 (4): 90. 